\title{
Juan José Lanz. Juan Ramón Jiménez y el legado de la Modernidad. Barcelona: Anthropos, 2017, 270 páginas
}

Mario Martín Gijón

Martín Gijón, M. (2021). Juan José Lanz. Juan Ramón Jiménez y el legado de la Modernidad. Barcelona: Anthropos, 2017, 270 páginas. Revista de Filología y Lingüística de la Universidad de Costa Rica, 47(2), e46948. doi: https://doi.org/10.15517/rfl.v47i2.46948

\section{(c) $\mathbb{P Q \Theta O}$}

Doi: https://doi.org/10.15517/rfl.v47i2.46948

URL: https://revistas.ucr.ac.cr/index.php/filyling/index 
Revista de Filología y Lingüística de la Universidad de Costa Rica

ISSN: 0377-628X

ISSN: 2215-2628

filyling@gmail.com

Universidad de Costa Rica

Costa Rica

\section{Juan José Lanz. Juan Ramón Jiménez y el legado de la Modernidad. Barcelona: Anthropos, 2017, 270 páginas}

Gijón, Mario Martín

Juan José Lanz. Juan Ramón Jiménez y el legado de la Modernidad. Barcelona: Anthropos, 2017, 270 páginas

Revista de Filología y Lingüística de la Universidad de Costa Rica, vol. 47, núm. 2, e46948, 2021

Universidad de Costa Rica, Costa Rica

Disponible en: http://www.redalyc.org/articulo.oa?id=33266553004

DOI: https://doi.org/10.15517/rfl.v47i2.46948

\section{(c) $(1) \Theta(9)$}

Esta obra está bajo una Licencia Creative Commons Atribución-NoComercial-SinDerivar 3.0 Internacional. 


\section{Juan José Lanz. Juan Ramón Jiménez y el legado de la Modernidad. Barcelona: Anthropos, 2017, 270 páginas}

Mario Martín Gijón

Universidad de Extremadura, Cáceres, España

marting@unex.es

(iD https://orcid.org/0000-0002-4155-1509
DOI: https://doi.org/10.15517/rfl.v47i2.46948

Redalyc: http://www.redalyc.org/articulo.oa?id=33266553004

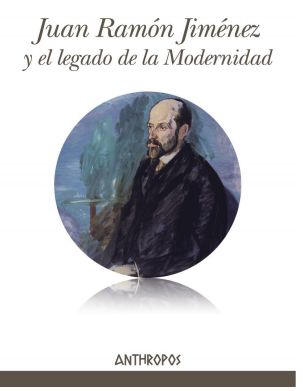

Lanz Juan José. Juan Ramón Jiménez y el legado de la Modernidad. 2017. Barcelona. Anthropos. 270pp.

La obra de Juan Ramón Jiménez (1881-1958), que marcó durante medio siglo la lírica española y obtuvo, en 1956, el reconocimiento de ser uno de los muy escasos poetas en castellano en recibir el Premio Nobel, no pasa, seguramente, por uno de sus mejores momentos en cuanto a número de lectores e influjo sobre los poetas actuales. Víctima de las "lecturas muertas" que, como diría Roland Barthes, se aplican tantas veces a los autores que se establecen en el canon de manera indiscutible, se ha perdido de vista la innegable novedad e influencia que alcanzaron sus versos en vida del autor.

Ya en 1981, el poeta y crítico José Miguel Ullán lamentaba la "imagen blandengue y cursilona que se nos ha vendido como fotografía de cuerpo entero para identificar a trote a aquel poeta que se sacó de la manga a un borrico peludo y suave", y es tristemente cierto que a uno de los mayores poetas españoles la inmensa mayoría solo puede, si acaso, asociarlo con Platero y yo. Etiquetado por otros, muchas veces sin leerlo, como poeta retirado en su torre de marfil, narcisista y al margen del compromiso (basta, además de conocer su exilio, leer su libro Guerra en España, para ver qué falso es ese tópico y qué auténtica su fidelidad a la España republicana), parece su destino ser un poeta para poetas y lectores exigentes, únicos capaces de reconocer el empeño de su vida, dedicada a componer su obra. Ello seguramente juegue en su contra, en una época donde la poesía más exigente ve su espacio en España cada vez más reducido, ya no solo acorralada por la corriente figurativa de la "poesía de la experiencia", sino por su degeneración de los líricos de instagram, esos "interpoetas o poetanautas" adolescentes que se forman su pequeño parnasillo en las redes sociales, y cuya pírrica obra, en las palabras del poeta y crítico Eduardo Moga, no es sino "sensiblería pubescente".

En estas circunstancias, vale la pena recordar y situar críticamente el aporte de la obra de Juan Ramón Jiménez a la modernidad literaria, refugio ineludible para quienes aún crean en una posibilidad de la escritura como conocimiento al margen del entretenimiento banal de los juegos postmodernos. Es lo que hace Juan José Lanz en el libro que analizamos, y que recoge, como explica en su prólogo, "un conjunto de trabajos realizados a lo largo de los últimos quince años, que se han centrado en la obra de Juan Ramón Jiménez" (p. 5). Juan José Lanz, profesor de literatura española en la Universidad del País Vasco, se ha distinguido desde hace ya muchos años por una amplísima labor investigadora caracterizada tanto por su rigor como por su 
variedad: frente a otros críticos que claramente muestran, en la selección de sus trabajos, una preferencia por una estética determinada, el profesor Lanz ha escrito trabajos fundamentales sobre autores tan distintos como Blas de Otero, Gabriel Celaya, Antonio Gamoneda, José Ángel Valente, Jaime Gil de Biedma, Luis Alberto de Cuenca, Diego Jesús Jiménez, Pere Gimferrer o José Miguel Ullán, entre muchos otros.

El presente trabajo se basa en un conocimiento exhaustivo de la obra de Jiménez, que se muestra ya desde el principio con la lista de "Abreviaturas de obras de Juan Ramón Jiménez" (pp. 9-13) y que abarca casi un centenar de títulos. El primer capítulo, "El legado poético de Juan Ramón Jiménez y la Modernidad” (pp. 15-36), comienza por recordar los argumentos del jurado del Nobel para galardonarlo, aunque también menciona que contó con el "apoyo fervoroso" (p. 15) de C. M. Bowra, prestigioso catedrático de poesía en Oxford. En su análisis, Lanz se basa en la propia confesión del poeta: "Tres veces en mi vida, a mis 19, a mis 33, a mis 49 años, salí de mi costumbre lírica conseguida a explorar con el ánimo libre el universo poético. Tres revoluciones íntimas, tres renovaciones propias, tres renacimientos míos". La trayectoria poética de Jiménez, como es sabido, logró combinar con excelencia el proyecto estético de la modernidad en occidente con la más rica tradición, tanto culta como popular, de España. Esa vertiente nacional, con todo, nos ha hecho perder de vista que su personal camino poético estaba en sintonía con los grandes debates intelectuales de su tiempo, y Lanz se extiende en paralelismos con el pensamiento de Heidegger (pp. 23-24), auctoritas que siempre parece dar un barniz de respetabilidad a todo, pero que quizás aquí no sea tan relevante, dado el mutuo desconocimiento entre ambos, salvo en lo relativo a las reflexiones del pensador alemán sobre Stefan George, poeta con el que Jiménez, aún sin tener ninguna relación con él, muestra algunos notables paralelismos.

El capítulo II, "Intimidad y discurso en la poesía primera de Juan Ramón Jiménez" se centra en esa época inicial y muestra cómo en libros como Arias tristes (1904), los críticos más agudos, como Antonio Machado, supieron ver una inédita modernidad en la "expresión del sentimiento", algo que lectores más superficiales no llegarían a calar, quedándose solo con la musicalidad subyugadora de los poemas. Como describe Lanz certeramente, "la conciencia es, por lo tanto, para Juan Ramón Jiménez, agente activo que ordena el universo en diálogo consigo mismo; pero es también un elemento receptivo que se manifiesta en la contemplación" (p. 47).

El capítulo III, "Platero y yo y la pedagogía nacional" aporta un novedoso punto de vista sobre esa obra tan conocida como mal entendida, pues desde el principio se la incluyó como lectura en los colegios. Aunque vinculada claramente con el amplio proyecto educativo de raíz krausista de la Educación Libre de Enseñanza (y con un trasfondo de tolerancia por el que no sorprende que fuera retirado de los colegios durante la dictadura franquista), la obra tiene un calado mucho mayor, siendo una muestra de la "experimentación en la prosa lírica” (p. 90) que influye tanto en la novela lírica de Azorín o Miró como en el poema en prosa que alcanzará su mejor concreción en Ocnos, de Luis Cernuda, un autor cuyos inicios fueron muy influidos por Jiménez.

Siguiendo una ordenación diacrónica, el capítulo IV, “En torno a Belleza (en verso) (1917-1923) y la segunda época poética" se centra en ese libro, Belleza que, cuando se publicó, como dice Lanz, "nadie pensaba que estos iban a ser los últimos poemarios [...] que Juan Ramón Jiménez iba a publicar hasta su exilio" (p. 91), algo llamativo en un autor que hasta entonces había mantenido un "ritmo frenético de producción" (p. 93) y que se justifica por ser la culminación de una etapa creativa, la que siguiendo al propio autor y al temprano análisis de Pedro Salinas, se considera la de la "poesía desnuda", marcada, como documenta el profesor vasco, por cómo en la balanza de lecturas del poeta andaluz comienza a pesar más la lectura de líricos de lengua inglesa, como Emily Dickinson, que lo llevan hacia unos versos cada vez más sencillos y despojados.

La última etapa de su obra se inscribe en el desarraigo del exilio, y en ella se sitúan los capítulos V y VI, "En torno a Romances de Coral Gables (1948) y la poesía del primer exilio" y "Juan Ramón Jiménez y Albert Einstein: a vueltas con el cronotopo en Espacio y Tiempo". El primero de estos capítulos se abre con un detallado relato de las circunstancias de Jiménez en la guerra y el exilio (pp. 135-143), una etapa dura que empezó a suavizarse a partir de la mudanza a Coral Gables, en el Estado de Florida, en el otoño de 1939. 
Lanz analiza las coordinadas de "espacio y tiempo en Coral Gables" (pp. 147-156) que tan decisivas serán en sus dos obras siguientes, cumbres de la lírica en castellano. Análisis impecable el de estos romances, en el que solo echamos en falta recordar que la forma elegida no era casual, dado que fue la preferida en la poesía bélica en la España republicana, tanto por poetas "de oficio" como por cientos de "vocaciones incipientes" surgidas en el frente, según la famosa distinción de Serge Salaün. En el capítulo VI, Lanz analiza cómo Tiempo y Espacio, desde la poesía, dialogan con la ciencia y la filosofía coetáneas. Queda abierta la cuestión de por qué la lírica de Jiménez, pasados los años siguientes al Nobel, y frente a su excelente recepción en algunos países latinoamericanos (Cuba especialmente) no ha interpelado apenas a poetas o pensadores extranjeros, al contrario que García Lorca. Las circunstancias de su exilio, y la escasa suerte que tuvo con sus traductores, podrían explicarlo en parte.

El capítulo VII, "El ondear del aire: Juan Ramón Jiménez y la poesía española de posguerra (1939-1960)" es, a nuestro juicio, el más valioso y un aporte ineludible a la historia de la poesía española contemporánea. Para la historia quedó aquella polémica exclusión de Jiménez de la antología Veinte años de poesía española (1939-1959), preparada por Josep Maria Castellet y justificada por la "pérdida de vigencia histórica" del poeta, según el crítico catalán. La realidad era mucho más compleja y, si ya José Luis García Martín analizó la "historia secreta" de la recepción de Jiménez bajo una dictadura que lo tenía aún por persona non grata, Lanz pone en juego sus dilatados conocimientos de la poesía de postguerra para registrar su patente influencia en poetas tan diversos como Ángel González, Blas de Otero, Gil de Biedma o José Ángel Valente. En definitiva, en cualquier poeta de cierta importancia de los que escribieron bajo la dictadura. Es, con todo, una pena que el análisis de esa recepción no tuviera también al menos una cala en la actualidad: a tenor de lo que se observa, uno tiene la impresión de que, si Lorca, Cernuda o Machado siguen siendo muy leídos (y no digamos Neruda), la obra de Juan Ramón Jiménez va quedando solo para filólogos. En nuestra sociedad postmoderna de redes, horizontal y sin ningún centro salvo el que señale el cursor del ratón en la pantalla, a muchos resulta, por desgracia, ajena la enorme ambición que los fundadores de la literatura moderna pusieron en la palabra.

Completa el libro un apéndice con comentarios de poemas de Juan Ramón Jiménez, excelente coda de carácter didáctico y buena ayuda para los profesores de secundaria, o al menos los que sigan realizando comentarios de texto en clase. En conclusión, un libro que, gracias a un bagaje filológico de los más acreditados, nos recuerda y nos demuestra la vigencia y el aporte inconmensurable de un poeta sin el cual, como dijera José Hierro, no puede entenderse nuestra lírica contemporánea. 